\section{History of Controlled Environment Horticulture: Greenhouses}

\author{
Krishna Nemali \\ Department of Horticulture and Landscape Architecture, Purdue University, \\ West Lafayette, IN 47907
}

Additional index words. evaporative cooling, geothermal heating, high-pressure sodium lamp, hydroponics, light-emitting diodes, Venlo style

\begin{abstract}
Modern greenhouses are intensive farming systems designed to achieve high efficiency and productivity. Plants are produced year-round in greenhouses by maintaining the environment at or near optimum levels regardless of extreme weather conditions. Many scientific discoveries and technological advancements that happened in the past two centuries paved the way for current state-of-the-art greenhouses. These include, but are not limited to, advancements in climate-specific structural designs and glazing materials, and temperature control, artificial lighting, and hydroponic production systems. Greenhouse structures can be broadly grouped into four distinct designs, including tall Venlo greenhouses of the Netherlands, passive solar greenhouses of China, low-cost Parral greenhouses of the Mediterranean region, and gutter-connected polyethylene houses of India and African countries. These designs were developed to suit local climatic conditions and maximize the return on investment. Although glass and rigid plastic options are available for glazing, the development of low-cost and lightweight plastic glazing materials (e.g., polyethylene) enabled widespread growth of the greenhouse industry in the developing world. For temperate regions, supplemental lighting technology is crucial for year-round production. This heavily relies on advancements in electro-lighting during the 19th and 20th centuries. The development of hydroponic production systems for the controlled delivery of nutrients further enhanced crop productivity. This article addresses important historical events, scientific discoveries, and technological improvements related to advancements in these areas.
\end{abstract}

Greenhouse cultivation involves growing crops inside structures covered with a transparent material that protects from extreme weather and unfavorable climatic conditions. In addition to greenhouses, there are other forms of protected cultivation, including rowcovers, low and high tunnels, and net houses. A greenhouse differs from others mainly in its (higher) level of technology and (permanent) nature of structural components used for construction. From a hobby-scale operation in the 19th century, greenhouses have evolved into realistic commercial-scale operations in the present century. Ornamentals, vegetables, aromatic plants, and medicinal plants can be grown in all climatic zones of the world inside greenhouses. It is estimated that the area under greenhouse vegetable production in 2019 was 496,800 ha (HortDaily, 2019). Nearly $80 \%$ of the area under greenhouses is located in eight countries: China, Spain, South Korea, Japan, Turkey, Italy,

Received for publication 27 July 2021. Accepted for publication 4 Oct. 2021.

Published online 13 January 2022.

This manuscript is based on a workshop sponsored by the History of Horticulture Working Group at the Annual Conference of the American Society for Horticultural Science, 2019.

K.N. is the corresponding author. E-mail: knemali@purdue.edu.

This is an open access article distributed under the CC BY-NC-ND license (https://creativecommons. org/licenses/by-nc-nd/4.0/).
Morocco, and France (Sabir and Singh, 2013). Countries like the Netherlands and Israel, in addition to their significant greenhouse areas, are major suppliers of greenhouse technology to many developing countries. The observed growth of the greenhouse industry is mostly associated with technological advancements in design, low-cost and durable glazing materials, environmental control (especially related to temperature and light), and hydroponic or soilless production.

\section{The Beginning}

The earliest record of producing crops using protected structures dates back to 14 to 37 CE in Rome (Paris and Janick, 2008). Artificial methods were used to grow $\mathrm{Cucu}$ mis plants year-round for Emperor Tiberius. Plants on carts were moved into protected houses, known as Specularia, during cold nights. A treatise on crop husbandry, known as Sanga Yorok, compiled by the royal physician of the Joseon dynasty of Korea during the $1450 \mathrm{~s}$, also documents the use of protected cultivation (Rajesh et al., 2020). The writings indicate the use of Ondol, a traditional underfloor heating system, to grow mandarin (citrus) plants and ripen the fruit. In the 17th and 18th centuries, structures called Orangeries were used in France to protect fruit trees from cold temperatures (Wearn and Mabberley, 2016). These structures were tall masonry buildings with large glass windows on the southern side to allow sunlight. Fruit trees like oranges grown in pots were moved into these structures during winter for protection from cold temperatures. Wye House in Maryland (Fig. 1) is the oldest surviving Orangery in the United States. Recent evidence suggests that the workers at Wye House conducted agricultural trials of medicinal and food plants (Blair et al., 2008). In the 19th century, large glasshouse conservatories were built in Europe to grow exotic tropical plants collected from other countries. For example, large wrought iron glasshouse structures were built at the conservatory of the Royal Horticultural Society in Cheswick (1840) and Royal Botanic Society in Regent's Park (1842-46) in England. These advances in structural design during the 18th and 19th centuries had a significant impact on greenhouse designs developed during the 20 th century.

\section{Greenhouse Designs}

Modern commercial greenhouses look vastly different from the Orangeries of the 18 th century and glasshouses of the 19th century. Greenhouse structural designs were developed mostly to suit local climatic conditions. Many commercial-scale greenhouses became operational during the 20th century in the Westland region of the Netherlands. The Westland-style greenhouses had removable glass sheets to allow rain during winter for draining the salts accumulated in the soil (Berkers and Geels, 2011). However, these greenhouses were poorly insulated because of gaps between plates, although they were much improved compared with the earlier designs used for grape cultivation in the Netherlands. The Westland greenhouses suffered significant damage during World War II. It was estimated that 1.8 million square meters of horticultural glass belonging to greenhouses were damaged because of the war (Berkers and Geels, 2011). During the reconstruction phase following the war, engineers in a city called Venlo developed a multispan, tall, glass, insulated greenhouse design called Venlo style. These greenhouses were built to meet domestic demand and export potential for vegetables after the war. Research partnerships established between the greenhouse industry and Wageningen University after the war further aided in advancing greenhouse technology. Venlo-style greenhouses are built with wide aluminum or steel trusses to provide sufficient strength to withstand high winds and snow loads, which are common for the region (Fig. 2A). The Venlo-style design allows for wide working spaces because the requirement of load-bearing posts is reduced because of trusses. In addition, the design allows good sunlight transmission into the structure. The salt problem in the soil was taken away by flushing with sprinklers and drainage systems in the Venlo greenhouses. Tomato exports from the Netherlands to Germany and England significantly increased after World War II. This can be attributed to the adoption of the Venlo-style design in the Westland region of the Netherlands (Berkers and Geels, 2011). 


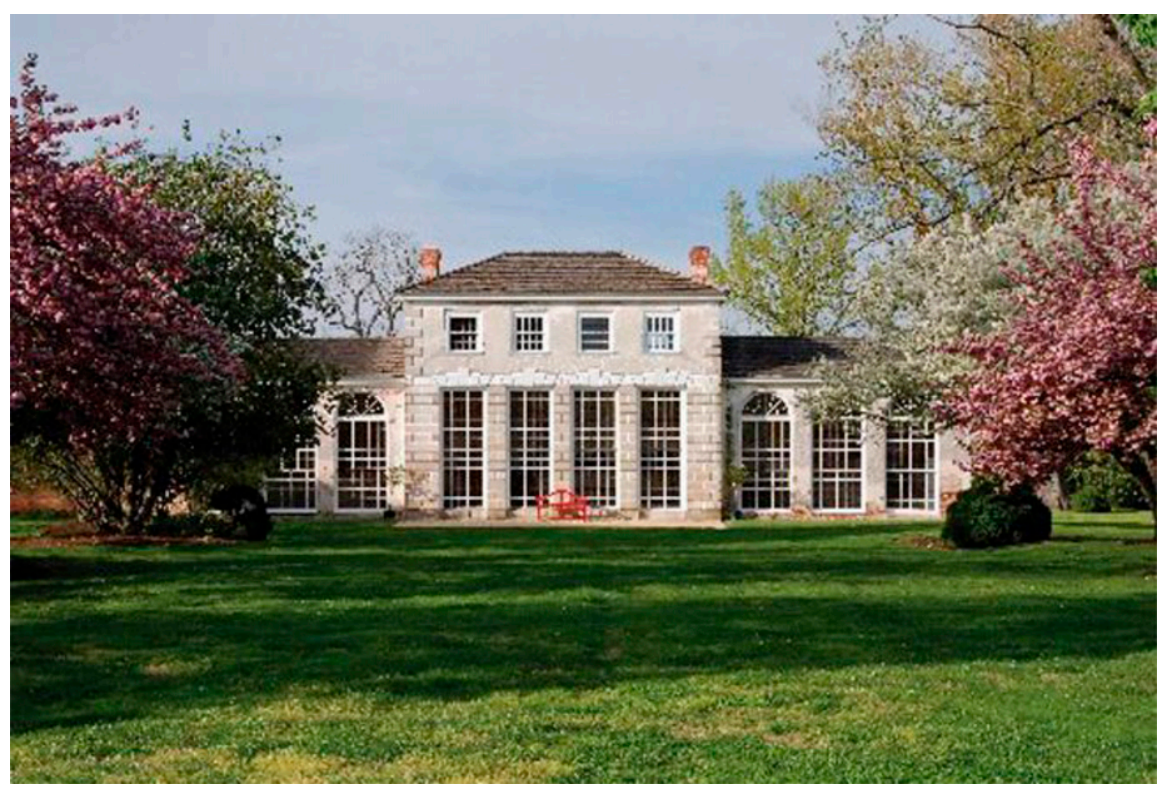

Fig. 1. Picture of Wye house in Maryland. This is the oldest surviving Orangery in the United States (photo by Warren Cox, courtesy of the Wye House Collection).

During the past several decades, the Venlo design has changed, especially to increase the ventilation rate and decrease overall cost. These changes made the Venlo style versatile for regions receiving relatively less wind than coastal areas (e.g., continental regions). Today, the Venlo region is one of the major centers for the greenhouse market in the world, and Venlo-style greenhouses are popular in many regions of the world.

In China, protected cultivation of ornamentals and vegetables started to increase during the 1980s. This can be attributed, in part, to the open door policy embraced by China in 1978, allowing trade equality among different countries. The open-door policy allowed Chinese growers to import modern greenhouse structures like Venlo designs. However, because of the high cost of Venlo greenhouses, the design was not popular. Today, the area covered by glass greenhouses in China is less than $1 \%$ (Costa and Heuvelink, 2004). Nevertheless, modern greenhouse designs helped Chinese greenhouse manufacturers to develop designs
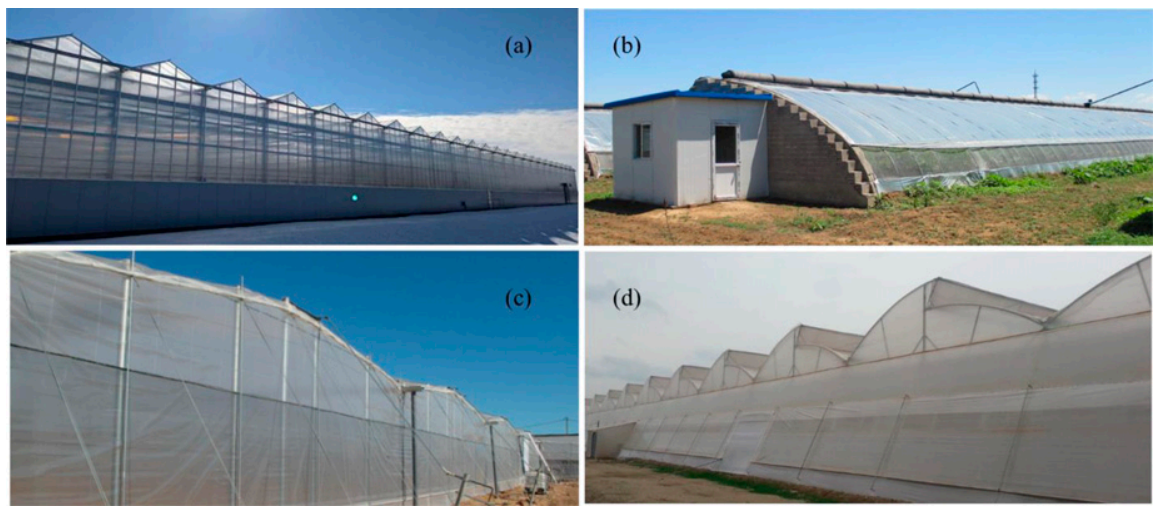

Fig. 2. Major commercial greenhouse designs seen in different regions of the world. (A) Venlo style (source: Pure Green Farms, Indiana). (B) Solar greenhouse (source: Vegetablecropshotline.org). (C) Parral style (source: Inveramel.com). (D) Gutter-connected polyhouse (source: author's collection).
Sea, there is the largest concentration of greenhouses (more than 26,000 ha) producing mostly vegetables for Europe (Patowary, 2013). Techniques such as hydroponics, soilless substrate production, mulching, and drip irrigation turned the region into what it is today (Fig. 3). The region also benefits from a large labor force from nearby countries in Africa. Parral-type greenhouse evolved in the Almeria region of Spain (Fig. 2C). These low-cost structures have plastic-covered, curved roofs and low gutter heights. The roof is nearly flat, and plastic film is held by metal strings. The film can be rolled to the gutter for ventilation during summer. In addition, ventilation can be provided from the sides by rolling the plastic upward. The Almeria region does not experience snow loads or high winds; therefore, a design was developed with plastic roofing and lightweight frames to keep the construction cost low. The plastic film holds heat inside the structure during winter, enabling vegetable production during cooler months. Research shows that the greenhouse area of Almeria is so large that the white roofs lower the temperature of the region by reflecting significant amounts of sunlight. The albedo of the region has increased since 1983, increasing sunlight reflectance by $9 \%$ (based on readings by Terra satellite, NASA) (Campra et al., 2008). However, the Almeria greenhouse industry has received much criticism in recent years. The intense greenhouse production in the Almeria region has been criticized by some for depleting aquifers and piling plastic along the countryside and sea, whereas others consider this region as an economic miracle (Baldock, 2018).

Different greenhouse designs evolved in semi-arid and tropical countries such as India, Malaysia, Kenya, and Morocco (Wageningen, 2015). The region has climate-related challenges such as high day/night temperatures, relative humidity, insects, and winds from monsoons and cyclones. The adopted greenhouse design consists of medium-totall, multispan, arch or gothic arch, gutterconnected polyethylene houses with side ventilation and roof ventilation (Fig. 2D). The main features of this design that lower the temperature are increased ventilation and shade nets. The roof ventilation is usually permanent (remains open) and covered with an insect net. In addition, thermal or shade screens are used to reflect sunlight and reduce the temperature inside the structure. The greenhouse has side ventilation along all four sides. The design protects from wind and rainfall during the monsoon season. These structures are used mostly for producing floriculture crops; however, more recently, there has been an increasing trend toward tomato and bell pepper production.

In the United States, many greenhouse designs are used to grow crops. These include the wide arch or gabled roof and Venlo-style greenhouse designs. Most greenhouse designs in the northern region of the country are gabled-style and built with a galvanized steel structure and glass or rigid plastic cover to withstand snow and wind. In warmer regions of the country, arch-style, gutter-connected, 


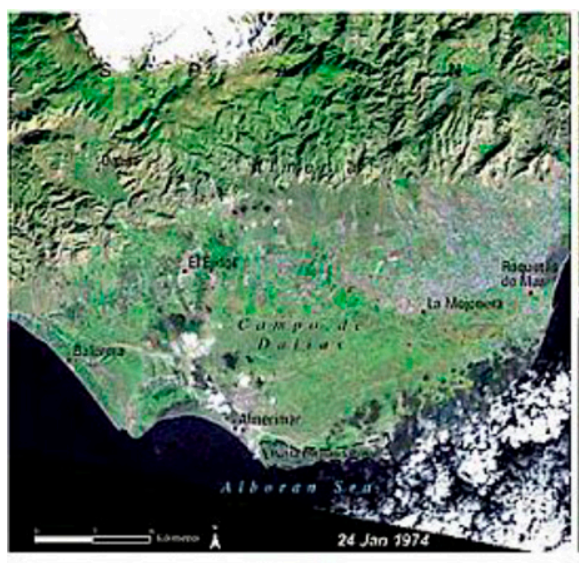

1974

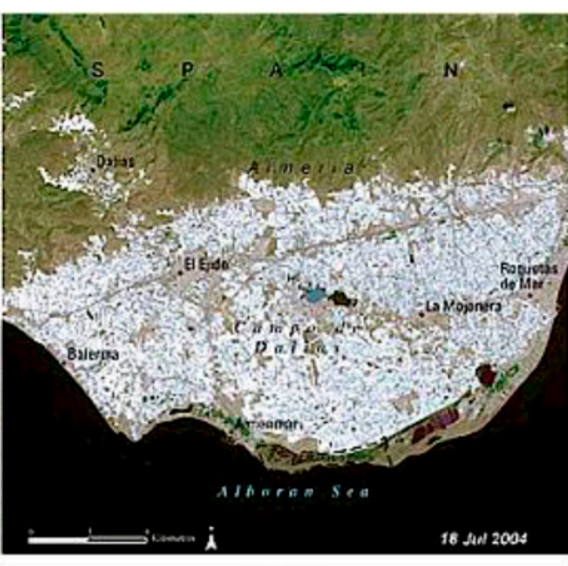

2004

Fig. 3. Growth of the greenhouse industry in the Almeria region of Spain during 30 years between 1974 and 2004. The white color refers to greenhouse roofs (source: UNEP, 2004).

plastic film greenhouses can be seen. In addition, structures called hoop houses (high tunnels) are increasingly becoming popular in the United States. These structures are different from greenhouses because plants are grown directly in the soil covered with plastic-covered structures. High tunnels allow for season extension and can be built at a fraction of the cost of a greenhouse (USDA NRCS, 2015).

\section{Glazing Materials}

Glazing (or cladding) material used to cover the superstructure can have a major impact on the greenhouse environment. It is the only barrier separating the outside environment and plants in a greenhouse. Transmission and distribution of light, air temperature, and relative humidity inside a greenhouse can vary by the type of glazing material. Glass was the earliest choice for glazing material until the early 1990s (Forbes, 1992). Because of its popularity, a tax was levied on glass manufacturers and customers from 1745 to 1845 in England. However, glass was expensive, and glasshouses in 19th century England were mostly built by the wealthy. During those times, beaver-tailed or curved glass panes became a popular design because they force rainwater away from wooden or wrought iron bars and toward the center of the pane (Jameson, 2013). Glass continued to be a popular choice, mainly because of its strength and good light transmission properties and, to some extent, because of the lack of other glazing options. In the 20th century, significant improvements were made in the quality of glass used for glazing. Float glass with perfectly smooth sides and patterned glass with matte or prismatic surfaces became available for greenhouses (Max et al., 2012). Although light transmission does not vary, prismatic glass has more diffused light (suitable for tropical climates with intense sunlight) than float glass (Victoria et al., 2012). Both annealed and tempered versions of float glass are commonly used in greenhouses. However, tempered glass has more strength (withstands more compression or tension) (Wageningen, 2018) than annealed glass and breaks into smaller pieces that rarely pose a risk to people. Therefore, tempered glass is used for covering greenhouse roofs. Both single-pane and double-pane (air layer between panes) glass is used in modern greenhouses. Double-pane glass has a lower thermal transmission (reduced heating costs) because of a layer of air between panes (Table 1). However, single-pane glass has become a common choice for modern greenhouses because of the higher cost of double-pane glass.

Today, polyethylene is the most widely used material for covering greenhouses. The accidental discovery of polyethylene in 1933 was an important milestone for modern greenhouses (Gibson, 1964). Polyethylene is produced by the polymerization of ethylene monomers. It formed accidentally when oxygen leaked into an overheated test vessel and provided the activation needed for the polymerization process (Jagger, 2008). Before the discovery of polyethylene, the high cost of glass limited the greenhouse industry to the developed world. In the 1950 s, polyethylene film covering was introduced as a glazing material for greenhouses. Because of the low cost and light weight of the glazing material and structure, polyethylene-covered greenhouses were much less expensive than traditional glass greenhouses. This aided in expanding the greenhouse industry to many regions of the world. The greenhouse industry grew rapidly by the end of the 20th century in many countries of Asia, Africa, and the Middle East (Giacomelli and Roberts, 1993; Max et al., 2012). Today, there are greenhouses in more than 115 countries (Sabir and Singh, 2013), and most of them are covered with plastic films. In the United States, Emery Myers Emmert, a professor at the University of Kentucky, conducted significant research in 1948 regarding the use of polyethylene as a greenhouse cover. During the 20th century, other types of plastic films, including ethylene vinyl acetate and ethylene butyl acrylate, also were identified as suitable greenhouse glazing materials. Plastic films used as greenhouse covers, especially those made from polyethylene, have low durability and high thermal transmission (Table 1). Chemical additives such as anti-fog, antidust, ultraviolet stabilizers, and infrared (IR) blockers were identified as additives to the polyethylene film for increasing the durability and decreasing thermal transmission (Blom and Ingrate, 1985; Espi et al., 2006; Max et al., 2012). Some plastic films containing fluorescent pigments that convert high-energy radiation (e.g., ultraviolet light) to other wavelengths used by plants (e.g., blue and red) were developed. However, because of the lack of sufficient data regarding their efficacy, such films have not been widely adopted (Espi et al., 2006; Hemming et al., 2006; Max et al., 2012).

Rigid plastics were developed as glazing materials for greenhouses in the 1990s. These include acrylic (commonly called plexiglass), polycarbonate, and PVC. These rigid plastics are intermediate to glass and plastic films. They have increased light distribution and decreased thermal transmission (Papadakis et al., 2000) compared with glass, but more durability than plastic films (Evonik Industries Ag, 2011). In addition, rigid plastics like polycarbonates do not transmit much

Table 1. Properties of different glazing materials used as greenhouse covering. ${ }^{\mathrm{z}}$

\begin{tabular}{|c|c|c|c|}
\hline Glazing material & Light transmission ${ }^{\mathrm{y}}(\%)$ & Thermal transmission $(\%)$ & Durability (years) \\
\hline Glass: single pane & $88-93$ & 3 & $25+$ \\
\hline Glass: double pane & $75-80$ & $<3$ & $25+$ \\
\hline Rigid plastic: single layer & 90 & $<3$ & $10-15$ \\
\hline Rigid plastic: double layer & $78-82$ & $<3$ & $10-20$ \\
\hline Plastic film: single layer & 87 & 50 & $3-4$ \\
\hline Plastic film: double layer & 78 & 50 & $3-4$ \\
\hline Plastic film: double layer with IR blocker & 78 & $<20$ & $3-4$ \\
\hline
\end{tabular}

${ }^{\mathrm{z}}$ Sources: Energy Conservation for Commercial Greenhouses (NRAES-3) (Bartok, 2001).

${ }^{\mathrm{y}}$ Includes light wavelengths from 400 to $700 \mathrm{~nm}$.

IR $=$ infrared. 
ultraviolet radiation (Max et al., 2012). Polycarbonate-based rigid plastics are synthesized by polycondensation of phosgene (Max et al., 2012), a chemical that was widely used during the chemical warfare of World War I. An important milestone in the use of polycarbonates as glazing material was the development of a process that removes cognac-colored tints in the material in 1971. This resulted in new material that was nearly as clear as glass (Bayer Material Science, 2013).

\section{Greenhouse Heating Systems}

Temperature affects the growth and development of plants. The optimal temperature for germination, growth, and flowering is close to $20^{\circ} \mathrm{C}$ for many species (Nemali, 2021). Greenhouse heating is a common practice during winter in northern regions, especially above the $40^{\circ} \mathrm{N}$ latitude (Nemali, 2021). Both natural (passive) and artificial (active) methods are used for heating a greenhouse. Although solar and geothermal heating constitutes natural methods, artificial heating uses fuel, oil, electricity, or wood.

Short-wave radiation from the sun is a major source of heat for greenhouses. The discovery of IR by William Herschel in 1800 increased our understanding of heat gain/loss from greenhouses. The fruit walls of the 17th century in England, France, and the Netherlands (De Decker, 2016) used the concept of IR radiation as a source of heat. These masonry walls get warmer during the day by absorbing short-wave solar radiation and emitting heat to the surroundings in the form of long-wave IR radiation at night. Plants surrounding the fruit walls absorb IR radiation and remain warm during cooler nights. In addition, the fruit walls protected plants from winds. Solar greenhouses (Fig. 2B) in China are other examples that use passive heat from the sun as the source of energy for heating (Gao et al., 2010; Jiang et al., 2004). These greenhouses have a large roof area exposed to the southern side that allows a maximum amount of sunlight transmission into the greenhouse during the daytime. Heat gained by the greenhouse components and walls during the day is released as IR radiation at night. To prevent the IR radiation from leaving the greenhouse, a blanket was used to cover the greenhouse roof at night. Instead of blankets, modern-day greenhouses add IR blockers to the plastic film (Blom and Ingrate, 1985; Espi et al., 2006; Max et al., 2012) for reflecting the IR light into the greenhouse. In many modern greenhouses, energy curtains are used to reflect IR light into a greenhouse to reduce heat loss (cooler climates) or out of a greenhouse to reduce heat gain (warmer climates).

Geothermal heating is another method of passive heating. This method uses the heat in the ground to maintain a warmer temperature inside the greenhouse at night. The ground temperature at a depth of 6 to $10 \mathrm{~m}$ usually remains constant throughout the year and close to the average annual temperature of the region (Nemali, 2021). The concept of geothermal energy has been well-known for many centuries. Greeks and Romans used water and steam from hot springs in public baths. An example is geothermal space heating in the Roman city of Pompeii during the first century (Lund, 2018). The largest geothermal heating system is located in Reykjavík, Iceland; most of the homes have received geothermal water for space heating since the 1930s (Lund, 2018). In the United States, water from hot springs was supplied to homes in Boise, ID, in 1892 (Lund, 2018). Geothermal energy became more popular in the 1970s because of the oil crisis, increase in gas prices, and environmental concerns of using fossil fuels. At present, countries like the Netherlands and Hungary have significant greenhouse acreage heated during winter using geothermal energy.

Artificial heating is more common in many modern greenhouses. The earliest evidence of artificial heating was documented in Rome using a Hypocaust, or central heating, system (Brittanica, 2016). Other examples include Ondol floor heating, which was used in Korea during the 1400s (Rajesh et al., 2020), and Dutch Stoves or floor heating to force bulbs to bloom during the off-season in the 18 th century. Before the $1870 \mathrm{~s}$, greenhouses in the United States and Europe were heated using the heat generated from decomposing organic matter (Young, 1998). Plants grown in containers were placed on top of beds made with decomposing organic matter inside greenhouses (Fig. 4). The heat from the organic matter maintained a warm microclimate for plants. However, challenges with this method included a lack of control of heat and organic matter availability for larger greenhouses. In the mid-19th century, a flue heating system consisting of a wood-burning stove and duct that ran along the floor of the greenhouse was developed. The method enabled the control of heat inside the greenhouse by turning off the fuel to the stove; however, it needed constant monitoring when the stove was on. These two methods were replaced with water-heating systems in the 1870s (Young, 1998). This involved running hot water through pipes placed below benches, similar to modern bench-heating systems. Because the pipes were made of cast iron, they rusted heavily. The pipes were later replaced with wrought iron in the 1880 s. The water-heating system reduced heating costs because water could hold heat longer. Toward the 1880 s, steam heating was developed to supply heat through long pipes in large greenhouses. However, the cost of fuel for generating steam was higher than that required for heating water. In many modern greenhouses, heat from the combustion of fuels (e.g., propane and natural gas) is used to increase greenhouse temperatures during winter. Modern greenhouses use unit heaters (Fig. 5) for artificial heating (Nemali, 2021). With these heaters, fuel is continuously supplied to the burners. The flame from the burner heats the air inside a heat exchanger, which transfers heat to the incoming cooler air blown into the unit by a fan. The hot air from the heater enters the greenhouse and maintains a warm temperature. The heating process in modern greenhouses is highly controlled using automation and temperature sensors. In some modern greenhouses, hot water runs through the pipes that span the greenhouse for heating purposes.

\section{Greenhouse Cooling Systems}

The heat accumulated inside greenhouses can be high during the summer months in tropical and subtropical regions because of intense radiation from the sun. The heat, if not removed, can increase greenhouse temperatures to extreme levels. Greenhouse cooling is achieved using different methods such as shading, natural ventilation, forced ventilation, and evaporative cooling. The simplest

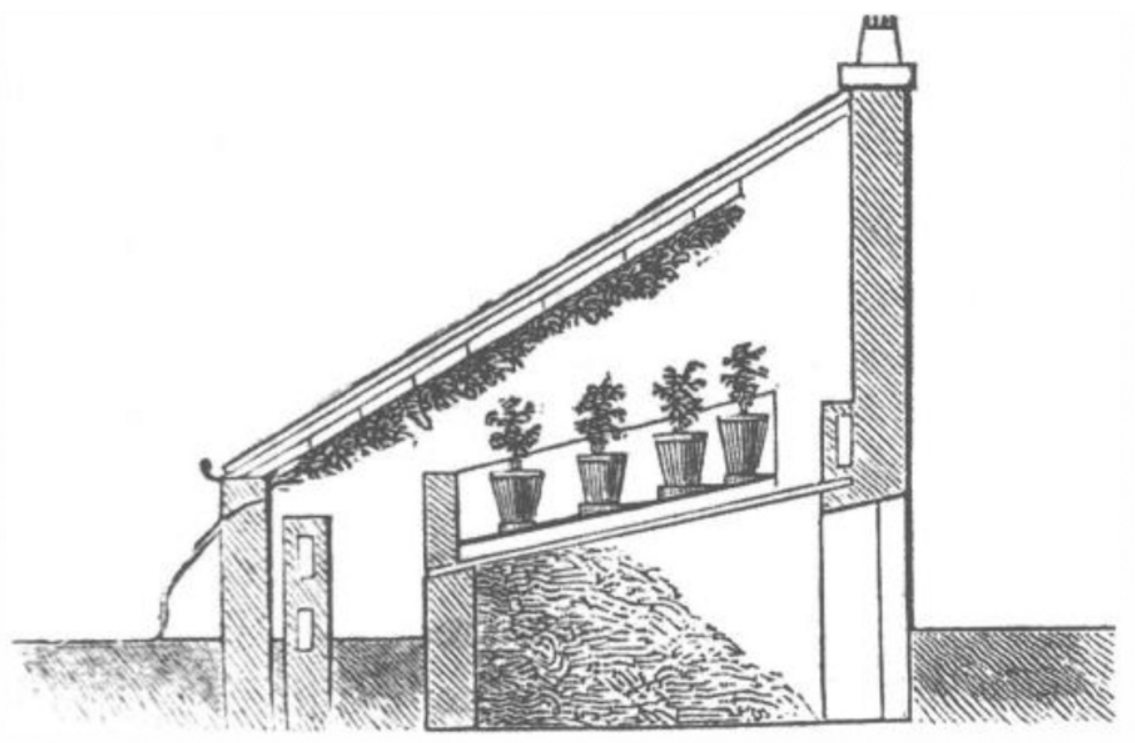

Fig. 4. A lean-to greenhouse shown with a pile of decomposing organic matter for heating containers (source: Young, 1998). 


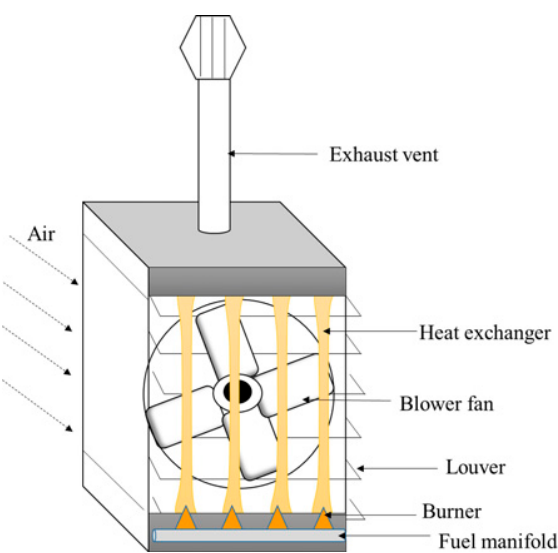

Fig. 5. Design of a unit heater used for heating greenhouses. Fuel is continuously supplied to the burner, which heats the air inside a heat exchanger. Fan blows air onto the heat exchanger, which increases the air temperature. The hot air enters the greenhouse.

of these methods is shading; however, this method also lowers the quantity of light received by plants. Therefore, other methods like natural ventilation, cooling pads, and exhaust fans are used in combination with shading.

Many modern greenhouses use the evaporative cooling method to lower the temperature. The principle involves heat exchange between warm air and cool water. Heat transfer happens when warm air is in contact with cool water, which lowers the temperature of the air. Water evaporates by absorbing heat from the air and increases humidity. It is believed that the concept of evaporative cooling was first used in ancient Egypt. Wet clothes were hung along the airways of palaces to keep the air cooler for royals. Recently, archeologists in the Persian Gulf unearthed an ancient air conditioning system that used the evaporative cooling technique (Vilikovska, 2016). A complex system of canals was found in the lower portion of a building. It is believed that a windcatcher at the top of the building was used to direct air over the underground water canals and cool air was diverted to enter the building. The invention of the psychrometric chart by Willis Carrier in 1904 helped to quantify the temperature decrease caused by evaporative cooling in greenhouses (Fig. 6). The chart can be used to measure the wet bulb temperature for a given relative humidity and dry bulb or ambient air temperature. The wet bulb temperature is the theoretical minimum temperature attributable to evaporative cooling. This allowed greenhouse manufacturers to design the correct type of cooling system for specific climates. In the United States, evaporative cooling was first used in Arizona. In 1908, Oscar Palmer Sr. built the first drip-type evaporative cooler in Arizona (Cunningham, 1985). Until the 1950 s, greenhouses in the United States were cooled by natural or forced (or fan) ventilation methods. Evaporative coolers were used in greenhouses after 1954 in the United States. Fogging, which involves the suspension of fine water droplets in the air, is another method of evaporative cooling used in modern greenhouses. The water droplets suspended in air exchange heat with air. This decreases the temperature and increases the relative humidity of the air. In 1995, a useful guide for calculating heating, ventilating, and cooling requirements in greenhouses was developed by the American Society for Agricultural and Biological Engineers (ASABE, 1995). At present, many greenhouses in the

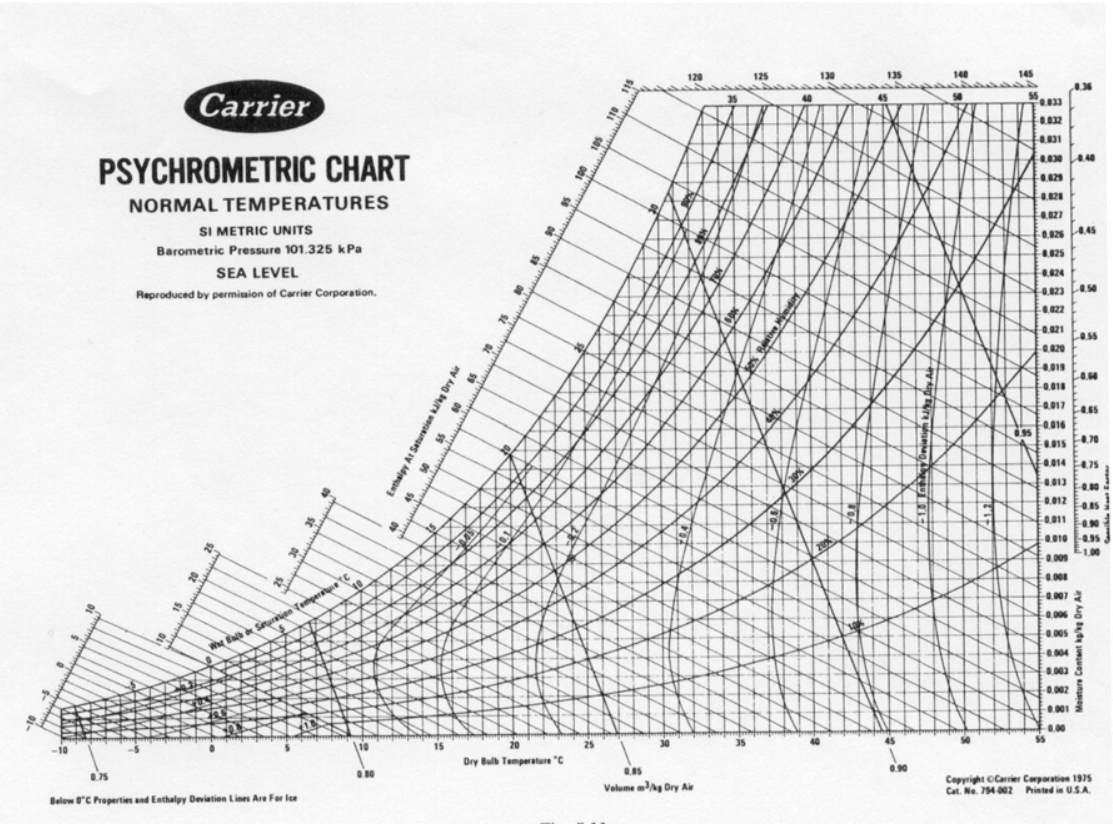

Fig. 6. Psychrometric chart invented by Willis Carrier. The chart provides wet-bulb temperature values for a given dry (ambient) temperature and relative humidity level. The wet-bulb temperature is the minimum temperature that can be obtained by the evaporative cooling method. southwestern United States use evaporative cooling methods to cool greenhouses.

However, in many warmer regions of the world, evaporative cooling is less effective because of high humidity levels in the air. In these regions, natural/forced ventilation combined with shade nets is the most common method of cooling greenhouses. The design of greenhouses (Fig. 2C and D) allows for both roof ventilation and side ventilation to remove heat. More recently, designs with partial or complete roof cover openings are being developed for warmer regions of the world. Evaporative cooling combined with forced ventilation is mostly limited to research or small-scale greenhouses in these regions of the developing world.

\section{Artificial Lighting}

In many modern greenhouses located in the northern regions, artificial lighting is used to supplement low levels of sunlight received during winter. Artificial lighting is critical to producing good-quality crops year-round in these regions. The present artificial lighting technology can generate energy-efficient, high-intensity, customizable light to provide specific wavelengths to plants. Elegant discoveries in the field of electrolighting have advanced greenhouse lighting technology to its current state.

Controlling the light environment for crops dates back to 14 to $37 \mathrm{CE}$. Roman gardeners used cucumber houses glazed with sheets of a material called Lapis Specularis (a form of gypsum) (Nordey et al., 2017; Paris and Janick, 2008). These houses were called Specularia. Although sheets of Lapis Specularis were used to protect plants from exposure to cold temperature, the material was diaphanous (or transparent) and allowed some light to pass into the cucumber houses. In the 19th century, plant collectors in England were eager to grow tropical plants in glasshouses. Because most of the tropical undercanopy plants, such as palms, prefer low light levels, the Palm House in the Royal Botanical Gardens, Kew (1840-48), used copper-tinted glass as glazing to reduce light transmission into the glasshouse (Schoenefeldt, 2011)

Electric lighting began with the discovery of the carbon-arc lamp (Fig. 7A) by Sir Humphry Davy (England) and Vasily Petrov (Russia) in the first part of the 19th century. When powered, the carbon-arc lamp generates an electric arc through the air between two carbon rods and generates light. Brush electric company in Ohio was the first to commercialize carbon-arc lamps in the United States. Although carbon-arc lamps were not used in greenhouses, there is evidence that botanists of the 19th century were interested in testing plant growth under these lamps. For example, L.H. Bailey used brush arc lighting to study the effects of photoperiodism in greenhouses and found that carbon-arc lamps could hasten maturity in plants (Bailey, 1891).

The next in the line of major inventions was the incandescent bulb (Fig. 7B). Unlike a carbon-arc lamp, incandescent bulbs contained a filament or wire enclosed in a bulb. The 

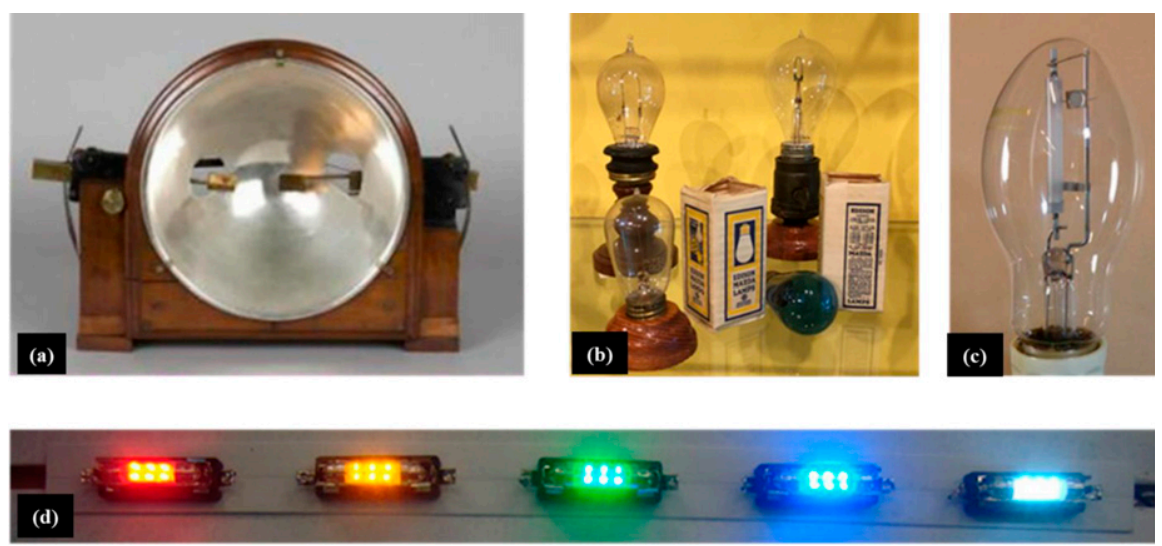

Fig. 7. Electric lighting models developed during the 19th and 20th centuries. (A) Carbon arc lamp. (B) Mazda incandescent lamp. (C) High-pressure sodium lamp. (D) Different colors of light-emitting diodes (source: Edisontechcenter.org).

filament glows when heated by electrical energy. Thomas Edison invented a carbon filament-based incandescent lamp. However, these incandescent lamps had a short life span and consumed more electricity. The invention of ductile tungsten by William Coolidge of the General Electric Company revolutionized electric lighting. Tungsten filament-based incandescent lamps were called Mazda lamps, named after the Zoroastrian god of light. These lamps lasted longer and used less electricity. Unlike carbon-arc lamps, Mazda lamps were used in greenhouses. However, the light from Mazda lamps contained IR wavelengths, which made plants elongate (Roodenburg, 1940). Incandescent lamps were also used in classical experiments related to photoperiodism in plants (Garner and Allard, 1920).

The next discovery related to artificial lighting was the sodium vapor lamp in 1920 by Arthur Compton. The lamp had highenergy efficiency compared with the incandescent lamp, but it had poor color rendering (mostly yellow); therefore, it was not ideal for plants. Moreover, sodium metal inside the glass was corrosive and blackened the glass, further reducing the luminosity of the lamp. The discovery of a material called Lucalox, or aluminum oxide ceramic, by scientists working at General Electric Company was a critical step for the next advancements in technology (Smithsonian, 2020a). This material can resist the corrosive nature and high pressure and temperature of sodium. This paved the way for the discovery of high-pressure sodium (HPS), or Lucalox HPS, lamps by General Electric Company (Fig. 7C). The HPS lamps had better color rendering and lasted longer than low-pressure sodium vapor lamps (Smithsonian, 2020b). These singleended high-pressure sodium lamps quickly became the industry standard in modern greenhouses. Recently, double-ended HPS lamps with increased light output have become popular (Nelson and Bugbee, 2014).

Another giant leap in electric lighting happened with the discovery of light-emitting diodes (LEDs) (Fig. 7D). LED-based lighting is becoming popular because of its high energy efficiency, low thermal emission, and long functional life (Kong et al., 2019). The LED discovery is tied to a phenomenon called electroluminescence described by Henry Round. This phenomenon involves the emission of light from materials when electricity passes through them. It was discovered that semi-conductors like silicon and germanium doped with other elements can be used to generate light using electroluminescence. Using this technique, James Biard and Gary Pittman discovered the first IR LED from a gallium arsenide diode at Texas Instruments in 1961. The discovery was accidental while the researchers were developing a gallium arsenide semi-conductor. This followed the discoveries of red (1962) and yellow (1972) LEDs. The discovery of bright blue LED using the indium gallium nitride semi-conductor by Nakamura, Akasaki, and Amano in 1993 aided in developing white light from LEDs. The group received the Nobel Prize in 2014 for their work (Royal Swedish Academy of Sciences, 2014). Currently, LED manufacturers use a technique called phosphor conversion to produce different colors of light from blue LEDs (Kong et al., 2019). Research is progressing rapidly to develop LEDs that are less expensive and can generate more light with increased energy efficiency.

\section{Hydroponics}

Historically, greenhouses used locally available soils (e.g., loam) and supplemented them with organic media to grow crops in containers. However, soil-based media were heavy and required sterilization, which increased costs. The development of the hydroponic method of growing crops significantly increased crop productivity in commercial greenhouses. The term "hydroponics" refers to growing plants using either soilless or water culture techniques. Soilless media are composed of sterilized organic and/or inorganic components, which hold water and nutrients, whereas water culture involves growing plants in a solution enriched with nutrients. There are several advantages of both soilless and waterculture methods of production. Some of these include uniform nutrient supply, sterilized root-zone environment, controlled delivery of nutrients to plants, and easy transportation of plants.

The first documentation of producing plants using hydroponics comes from the Hanging Gardens of Babylon (Resh, 1990), supposedly built by King Nebuchadnezzar (604-562 BC) along the Euphrates River in Iraq. It was described that plants were grown at multiple levels in these gardens (Finkel, 1989), suggesting that soil was excavated from its natural location and likely mixed with lighter organic media to grow plants. The use of soilless media in greenhouses became popular in the 20th century. The research conducted by Lawrence and Newell in 1939 in England recommended the addition of sphagnum moss to regular soil for reducing pathogens and weeds and minimizing nutritional imbalances in plants (Bunt, 1988). Soilless substrates became popular horticulture media in the 1950s (Kitir et al., 2018). This can be attributed to the research performed at the University of California in the 1950s (Baker, 1957). Subsequently, many studies showed that organic material such as peat can be used as a good soilless medium to grow plants (Carlile et al., 2019). Currently, peat is the most commonly used organic component in soilless substrates. However, there has been a huge push for phasing out peat-based substrates because of increasing environmental concerns. Peat is a large carbon sink (stores $\approx 21$ to $33 \%$ of terrestrial organic carbon) (Gruda et al., 2019) and limited resource (covers only $3 \%$ of the earth's surface) (Gruda et al., 2019). Regeneration of peat is a slow process after extraction; therefore, the indiscriminate use of peat in the greenhouse industry can cause negative impacts on the environment. Therefore, many environmental scientists are developing alternate substrates that are more renewable (e.g., coir) than peat. Rockwool is another soilless and inorganic substrate that is extensively used. This is predominantly used for greenhouse vegetable production (e.g., tomato). It is estimated that, globally, more than 10,000 ha of greenhouses use rockwool as a soilless growing medium (Blok and Urrestarazu, 2010). Research and development related to soilless substrates are active areas in the United States and globally. Academic researchers at the North Carolina State University in the United States conduct extensive research of new materials for soilless substrates and study their physical and chemical properties.

The first attempt to grow plants using the water-culture method likely happened when researchers in the 17 th century recognized that soil is needed only to supply certain chemicals and water to plants. Woodward (1699) grew mint plants in water collected from the Thames River, rain, springs, and conduits, and concluded that plant growth was slower in water that did not contain any solutes (Hershey, 1994). In 1887, Julius von Sachs developed a method that involved a wide glass tube fitted with a cork stopper to grow plants in a solution containing dissolved nutrients (Fig. 8). The observations by Justus 


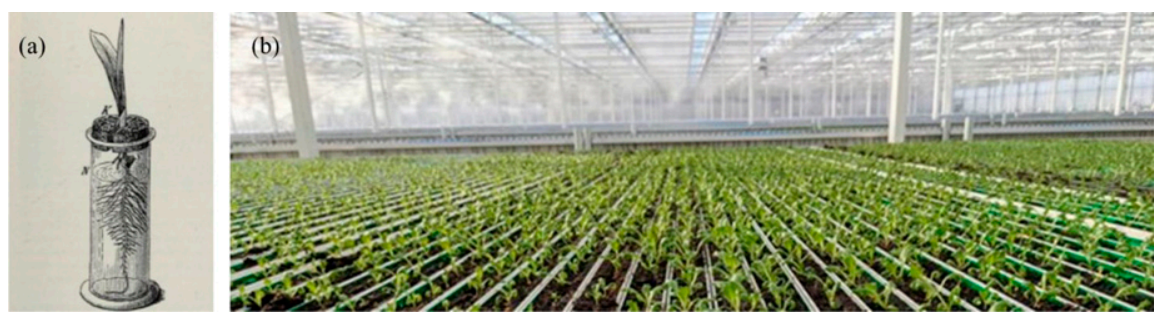

Fig. 8. (A) An illustration of a glass container with a cork stopper used by Julius von Sachs to grow plants in water enriched with elements (source: Soils.Wisc.edu). (B) A modern commercial hydroponics greenhouse with automated irrigation, nutrient delivery systems, and environmental control (source: Pure Green Farms, Indiana).

von Liebig regarding the requirement of elements, including nitrogen, phosphorus, potassium, calcium, magnesium, and sulfur, for plants (Marschner, 2003) further developed the foundation for the water-culture method. Between 1860 and 1938, the essentiality of micronutrients, including iron, manganese, boron, zinc, copper, and molybdenum (Table 2), was established. In the United States, Gericke (1929) from the University of California in Berkeley reported that water culture can be used to grow crops (Gericke, 1929). He coined the term "hydroponics" in 1937 for the method of growing plants in water enriched with nutrients (Gericke, 1937). Subsequently, Hoagland and Arnon from the University of California continued extensive work involving hydroponics and published several bulletins for the public and industry (Hoagland and Arnon, 1950). The importance of hydroponics as a method to grow crops became significant during the 1960s and 1970s in the United States. For example, Pan American Airways adopted hydroponic culture to grow vegetables for passenger meals on Wake Island, a refueling stop for transpacific flights. It was deemed expensive to ship vegetables to this island and impossible to grow vegetables on the island because of to its rocky habitat (Hershey 1994).

Science and technology related to hydroponics further improved because of extensive research conducted by the National Aeronautics and Space Administration (NASA) during the past three decades. There has been a huge interest in growing plants on the International Space Station and spaceflights to other planets during the past two decades. Plants grown on a spacecraft could supplement a healthy diet for astronauts and aid in clearing the air by absorbing carbon dioxide and adding oxygen. Because the dust from regular soil can be inhaled by astronauts and contaminate expensive machinery on a spacecraft, NASA began conducting and supporting research related to

Table 2. Discovery of different essential plant nutrients (adopted from Mineral Nutrition of Higher Plants by Horst Marschner, 2002).

\begin{tabular}{lcl}
\hline Nutrient & Yr & \multicolumn{1}{c}{ Discovered by } \\
\hline $\begin{array}{l}\text { Nitrogen, phosphorus, potassium, calcium, } \\
\quad \text { magnesium, and sulfur }\end{array}$ & 1840 & Justus von Liebig (based on observations) \\
Iron & 1860 & J. Sachs \\
Manganese & 1922 & J.S. McHargue \\
Boron & 1923 & K. Warington \\
Zinc & 1926 & A.L. Somner and C.B. Lipman \\
Copper & 1931 & C.B. Lipman and G. MacKinney \\
Molybdenum & 1938 & D.I. Arnon and P.R. Stout \\
\hline
\end{tabular}

hydroponics (NASA, 2010). Some interesting research conducted by NASA includes the study of the nutrient invasiveness of different crops like lettuce and radishes in hydroponic systems and real-time analyses of nutrient levels in hydroponic solutions (NASA, 2010). At present, many commercial hydroponic greenhouses (Fig. 8B) worldwide largely implement the research findings of NASA. It is estimated that there will be 2480 hydroponic operations in the United States by 2026 (IBIS World, 2021), and it will continue to grow in the future.

\section{Future Trends in Technology}

It is challenging to predict future innovations in greenhouse technology. The following trends are based on some of the current issues encountered by the greenhouse industry:

1. Greenhouses will likely have an important role in the future global food supply. Temperature increases caused by climate change will likely favor increased global food production in greenhouses in the temperate regions of the world. It is also likely that cooling technologies with higher efficiencies will be developed in the future for warmer regions of the world because of global warming.

2. It is anticipated that greenhouse automation will evolve into systems that are more intelligent in the future. An example is a system that can use Internet of Things (IoT) sensors to visualize plant growth and analyze plant biochemistry, make localized intelligent decisions, and adjust the growth

HortScience Vol. 57(2) February 2022 environment for maximizing yield, quality, and nutritional value without human involvement.

3. Future greenhouses will likely place more emphasis on the carbon footprint, especially by decreasing the use of fossil fuels and increasing the use of renewable energy sources.

4. Greenhouses of the future will likely use technologies that increase wateruse efficiency to compensate for the ever-decreasing freshwater resources.

5. As consumers become increasingly conscious about food safety, greenhouse production technologies that completely avoid pesticides and use nonchemical methods (e.g., ultraviolet sterilization) to control insects and diseases will likely be developed in the future.

\section{Literature Cited}

ASABE. 1995. Heating, ventilating and cooling greenhouses. ANSI/ASAE EP406.4. St. Joseph, MI $<$ http://ceac.arizona.edu/sites/default/files/asae_heating_ventilating_and_cooling_greenhouses.pdf.

Bailey, L.H. 1891. Some preliminary studies on the influence of the electric light upon greenhouse plants. Cornell Univ. Agr. Expt. Sta. Bull. 30:83-122.

Baker, K.F. 1957. The U. C. system for producing healthy container-grown plants: Through the use of clean soil, clean stock, and sanitation. University of California, Division of Agricultural Sciences, Agricultural Experiment Station, Extension Service. <https://ia600203.us. archive.org/14/items/ucsystemforprodu23bake/ ucsystemforprodu23bake.pdf/>.

Baldock, K. 2018. Reimagining Almeria's plastic sea of greenhouses. 11 July 2021. <https:// vertical-farming.net/blog/2018/04/02/reimaginingalmerias-agriculture $/>$.

Bartok, J.W. 2001. Energy conservation for commercial greenhouses. Natural Resource, Agriculture, and Engineering Cooperative Extension Service, Cornell University. 23 July 2011 $<$ https://ecommons.cornell.edu/bitstream/handle/ 1813/67126/NRAES-003.pdf?sequence=1\&is Allowed $=\mathrm{y} />$.

Bayer Material Science. 2013. History of polycarbonate at Bayer. 13 July 2021. < http://www. interwall.pe/sites/default/files/PCS_History.pdf/>.

Berkers, E. and F.W. Geels. 2011. System innovation through stepwise reconfiguration: The case of technological transitions in Dutch greenhouse horticulture (1930-1980). Technol. Anal. Strateg. Manage. 23(3):227-247, https://doi. org/10.1080/09537325.2011.550392/.

Blair, J.E., M.D. Cochran, S.N. Duensing, and M.P. Leone. 2008. Phase II Archaeological Testing on Wye Greenhouse (18TA314), Talbot County, Maryland, 2008. (umd.edu). 11 July 2021. $<$ http://hdl.handle.net/1903/15002/>.

Blok, C. and M. Urrestarazu. 2010. Substrate growing developments in Europe 2010-2027. Horticom Plataforma. <https://edepot.wur.nl/137023>

Blom, T.J. and F.J. Ingrate. 1985. The use of polyethylene film as greenhouse glazing in North America. Acta Hort. 170:69-80, https://doi.org/ 10.17660/ActaHortic.1985.170.7. 
Britannica. 2016. Hypocaust. Encyclopedia Britannica, 10 Aug. 2016. 13 July 2021. <https:// www.britannica.com/technology/hypocaust/ $>$.

Bunt, A.C. 1988. Media Mixes for Container Grown Crops. Unwin Yyman, London, https:// doi.org/10.1007/978-94-011-7904-1.

Campra, P., M. Garcia, Y. Canton, A. PalaciosOrueta. 2008. Surface temperature cooling trends and negative radiative forcing due to land use change toward greenhouse farming in southeastern Spain. JGR Atmospheres. https:// doi.org/10.1029/2008JD009912.

Carlile, W.R., M. Raviv, and M. Prasad. 2019. Soilless culture, p. 303-378. In: M. Raviv, H. Lieth, and A. Bar-Tal (eds.). Organic soilless media components. Elsevier. https://doi. org/10.1016/C2015-0-01470-8.

Chen, T.Y., T. Yamaguchi, and T. Kuroyanagi. 2000. Energy saving sun light greenhouse in China. J. Soc. Agr. Struc. Japan 31:113-118. $<$ https://edepot.wur.n1/331170>.

Costa, J.M. and E. Heuvelink. 2004. China's greenhouse horticulture: An overview, p. 7-41. In: J.M. Costa and E. Heuvelink (eds.). Greenhouse horticulture in China: Situation and prospects. Horticultural Production Chains Group, Wageningen, the Netherlands.

Cunningham, B. 1985. The box that broke the barrier: The swamp cooler comes to Southern Arizona. J. Ariz. Hist. 26:163-174.

De Decker, K. 2016. Fruit walls: Urban farming in 2016. 11 July 2021. < https://www.resilience. org/stories/2016-01-06/fruit-walls-urbanfarming-in-the-1600s $>$.

Espi, E., A. Salmeron, A. Fontecha, Y. Garcia, and A.I. Real. 2006. Plastic films for agricultural applications. J. Plast. Film Sheeting 22:85-102, https://doi.org/10.1177/8756087906064220.

Evonik Industries AG. 2011. Technical informations, PLEXIGLAS. Alltop SDP 16/980 (/1053,/1200) - 64, Product description. 1-2. 2 p. Darmstadt.

Finkel, I.L. 1989. The hanging gardens of Babylon, p. 38-58. In: P. Clayton and M. Price (eds.). The seven wonders of the ancient world. Dorset Press, New York.

Forbes, D.L. 1992. Glazing system, particularly for greenhouses. U.S. Patent 5,140,768. <https:// patents.google.com/patent/US5140768A/en/>.

Gao, L-H., M. Qu, H-Z. Ren, X-L. Sui, Q-Y. Chen, and Z. Zhang. 2010. Structure, function, application, and ecological benefit of a singleslope, energy-efficient solar greenhouse in China. HortTechnology 20:626-631, https:// doi.org/10.21273/HORTTECH.20.3.626.

Garner, W.W. and H.A. Allard. 1920. Effect of the relative length of day and night and other factors of the environment on growth and reproduction of plants. J. Agr. Res. 18:553-606, 10.1175/ 1520-0493(1920)48<415b:EOTRLO > 2.0.CO;2.

Gericke, W.F. 1929. Aquiculture-A means of crop production. Amer. J. Bot. 16:862.

Gericke, W.F. 1937. Hydroponics: Crop production in liquid culture media. Science 85:177-178, https://doi.org/10.1126/science.85.2198.177.

Giacomelli, G.A. and W.J. Roberts. 1993. Greenhouse covering systems. HortTechnology 3:50-58, https://doi.org/10.21273/HORTTECH.3.1.50.

Gibson, R.O. 1964. The Discovery of Polythene, The Royal Institute of Chemistry, Lecture Series 1964, Number 1, 1-30.

Gruda, N., M.B. Bisbis, and J. Tanny. 2019. Impacts of protected vegetable cultivation on climate change and adaptation strategies for cleaner production-A review. J. Clean. Prod. 225:324-339, https://doi.org/10.1016/j.jclepro.2019.03.295.

Hemming, S., E.A. van Os, J. Hemming, and J.A. Dieleman. 2006. The effect of new developed florescent greenhouse films on the growth Fragaria $\times$ ananassa 'El santa'. Eur. J. Hort. Sci. 71:145-154. <https://edepot.wur.n1/33119>.

Hershey, D.R. 1994. Solution culture hydroponics: history \& inexpensive equipment. Amer. Biol. Teach. 56:111-118, https://doi.org/10.2307/ 4449764.

Hoagland, D.R. and D.I. Arnon. 1950. The waterculture method for growing plants without soil. California Agriculture Experiment Station Circular 347, revised.

HortDaily. 2019, 2 Jan. World Greenhouse Vegetable Statistics updated for 2019. 11 July 2021. $<$ https://www.hortidaily.com $>$.

IBIS World. 2021. Hydroponic crop farming industry in the US. 13 July $2021 .<$ https://www. ibisworld.com/united-states/market-researchreports/hydroponic-crop-farming-industry/ $>$.

Jagger, A. 2008. Polyethylene discovered by accident 75 years ago. 11 July 2021. <https:// www.icis.com/explore/resources/news/2008/ 05/12/9122447/polyethylene-discovered-byaccident-75-years-ago/ $>$.

Jameson, R. 2013. Glasshouses: History and conservation of Victorian and Edwardian greenhouses and cold frames. 13 July 2021. <https://www. buildingconservation.com/articles/glasshouseconservation/glasshouse-conservation.htm/ $/$.

Jiang, W.J., D.Y. Qu, D. Mu, and L.R. Wang. 2004. Protected cultivation of horticultural crops in China. Hort. Rev. (Amer. Soc. Hort. Sci.) 30:115-162.

Kitir, N., E. Yildirim, U. Şahin, M. Turan, M. Ekinci, S. Ors, R. Kul, H. Unlu, and H. Unlu. 2018. Peat use in horticulture. Environ. Sci. (Ruse), https:// doi.org/10.5772/INTECHOPEN.79171.

Kong, Y., A. Nemali, C.A. Mitchell, and K. Nemali. 2019. Spectral quality of light can affect energy consumption and energy-use efficiency of electrical lighting in indoor lettuce farming. HortScience 54:865-872, https://doi.org/ 10.21273/HORTSCI13834-18.

Lund, J.W. 2018. Geothermal energy. Encyclopedia Britannica, 30 Apr. 2018. 13 July 2021. <https:// www.britannica.com/science/geothermal-energy $>$.

Marschner, H. 2003. Nutritional physiology: Introduction, definition, and classification of mineral nutrients, p. 3-5. In: H. Marschner (ed.). Mineral nutrition of higher plants. Academic Press, Elsevier, San Diego, CA.

Max, J.F.J., U. Schurr, H.-J. Tantau, U.N. Mutwiwa, T. Hoffman, and A. Ulhrich. 2012. Greenhouse cover technology, p. 259-398. In: J. Janick (ed.). Horticulture Reviews. Wiley-Blackwell, John Wiley \& Sons, Hoboken, NJ.

NASA. 2010. Pure Innovation. This spinoff shows how planning for long missions can lead to benefits back home. 13 July 2021 . <https:// www.nasa.gov/offices/oct/home/tech_life_asa_ analytics.html/>.

Nelson, J.A. and B. Bugbee. 2014. Economic analysis of greenhouse lighting: Light emitting diodes vs. high intensity discharge fixtures. PLoS One, https://doi.org/10.1371/journal.pone.0099010.

Nemali, K. 2021. Temperature Control in Greenhouses. (HO-327-W). 13 July 2021. <https:// www.extension.purdue.edu/extmedia/HO/HO327-W.pdf/>.

Nordey, T., C. Basset-Mens, H. De Bon, T. Martin, E. Déletré, S. Simon, L. Parrot, H. Despretz, J. Huat, Y. Biard, T. Dubois, and E. Malézieux. 2017. Protected cultivation of vegetable crops in sub-Saharan Africa: Limits and prospects for smallholders. A review. Agron. Sustain. Dev. 37:53, https://doi.org/10.1007/s13593-017-0460-8.

Papadakis, G., D. Briassoulis, G. Scaracia Mugnozza, G. Vox, P. Feuilloley, and J.A. Stoffers. 2000. Radiometric and thermal properties of, testing methods for greenhouse covering materials. J. Agr. Eng. Res. 77:7-38, https://doi.org/10.1006/jaer.2000.0525.

Paris, H.S. and J. Janick. 2008. What the Roman emperor Tiberius grew in his greenhouses? Proc. IXth EUCARPIA meeting on genetics and breeding of Cucurbitaceae, p. 33-41. $<$ https://www.hort.purdue.edu/newcrop/2_13_ Janick.pdf>

Patowary, K. 2013. The greenhouses of Almeria. 11 July 2021. <https://www.amusingplanet.com/ 2013/08/the-greenhouses-of-almeria.html/>.

Rajesh, T., D. Ramesh, K.S.S.N. Nagateja, and V. Pujari. 2020. Plant protection using cold frame, $p$. 1-12. In: V. Rani (ed.). Advances in life sciences, vol-1. Integrated Publications, Delhi, India.

Resh, H.M. 1990. Hydroponic home food gardens. Woodbridge Press, Santa Barbara, CA.

Roodenburg, J.W.M. 1940. Rec. Trav. Bot. Neerl. 37:303.

Royal Swedish Academy of Sciences. 2014. The Nobel prize in physics 2014. 13 July 2021. $<$ https://www.nobelprize.org/prizes/physics/ 2014/press-release/>.

Sabir, N. and B. Singh. 2013. Protected cultivation of vegetables in global arena: A review. Indian J. Agr. Sci. 83:123-135.

Schoenefeldt, H. 2011. The use of scientific experimentation in developing the glazing for the Palm House at Kew. Construction History 26:19-39, https://doi.org/10.2307/41613974.

Smithsonian. 2020a. Twentieth century inventors: High-pressure sodium lamp. 13 July 2021. $<$ https://americanhistory.si.edu/lighting/bios/ kswl.htm/>.

Smithsonian. 2020b. Energy efficiency: Light sources in the twentieth century. 13 July 2021. $<$ https://americanhistory.si.edu/lighting/tech/ chart.htm/>.

UNEP. 2004. An Overview of our changing environment 2004/5. Geo Year Book, United Nations Environment Programme. <http:// www.unep.org/geo/yearbook $>$.

USDA NRCS. 2015. High tunnel system. United States Department of Agriculture. Natural Resources Conservation Service. 2 Oct. 2021. <https:// www.nrcs.usda.gov/wps/portal/nrcs/detailfull/ national/programs/?cid=stelprdb1046250/>.

Victoria, G.N., F.L.K. Kempkes, P. Van Weel, C. Stanghellini, T.A. Dueck, and M. Bruins. 2012. Effect of a diffuse glass greenhouse cover on rose production and quality. Acta Hort. 952:241-248, https://doi.org/10.17660/ ActaHortic.2012.952.29.

Vilikovska, Z. 2016. Slovaks discover ancient air conditioning in Kuwait. 13 July 2021. <https:// spectator.sme.sk/c/20153276/slovaks-discoverancient-air-conditioning-in-kuwait.html/>.

Wageningen, U.R. 2015. The African Greenhouse. GTB-1360. Wageningen UR Greenhouse Horticulture Bleiswijk, The Netherlands. <https:// edepot.wur.nl/351439>.

Wageningen, U.R. 2018. Feasibility study of thin glasses for greenhouse roof designs. WPR-732. Wageningen UR, BU Greenhouse Horticulture, Bleiswijk, The Netherlands. https://doi.org/ 10.18174/432087.

Wearn, J.A. and D.J. Mabberley. 2016. Citrus and orangeries in northern Europe. Curtis's Bot. Mag. 33:94-107, https://doi.org/10.1111/curt.12128.

Woodward, J. 1699. Some thoughts and experiments concerning vegetation. Philosophical Transactions of the Royal Society 21:193-227, https://doi.org/10.1098/rstl.1699.0040.

Young, T. 1998. From manure to steam: the transformation of greenhouse heating in the US, 1870-1900. Agr. Hist. 72:574-596. <http:// www.jstor.org/stable/3744571>. 